\title{
LGK974 Potentiates the Lethality of TRAIL in Hepatocellular Carcinoma Cells by Inducing Apoptosis via Suppressing NF-кB Signaling Pathway
}

\author{
WEITI WU, FEI YAN, HUAZHONG CHEN, HUI SHAO, YONGZHI TANG AND XIAOYE CHEN ${ }^{1 *}$
}

Department of Infectious Diseases, 'Department of Radiotherapy, Taizhou Hospital, Zhejiang Province, Taizhou 317000, China

Wu et al.: LGK974 Enhanced the TRAIL-Mediated Lethality in Liver Cancer

LGK974 is a potent Wingless-related integration site inhibitor at Phase II of a clinical trial. However, little is known about its role and the underlying mechanisms in human hepatocellular carcinoma. 3-(4,5-Dimethylthiazol-2-yl)-2,5-Diphenyltetrazolium Bromide and colony formation assays were used to determine the cytotoxicity of LGK974 on liver cancer cell lines. Flow cytometry assay was performed to examine the cell apoptosis induced by LGK974 alone or in combination with tumor necrosis factorrelated apoptosis-inducing ligand. Western blot assay was used to evaluate the protein expression profiling of caspases, poly adenosine diphosphate-ribose polymerase and B-cell lymphoma 2 family, as well as the activation of signaling pathways. At the present study, we demonstrated that LGK974 can suppress human hepatocellular carcinoma cell proliferation by inducing apoptosis and suppress colony formation. In addition, LGK974 effectively inhibited the protein expression of B-cell lymphoma 2, while elevated the protein expression of B-cell lymphoma 2 homologous antagonist/killer, B-cell lymphoma 2 associated agonist of cell death and B-cell lymphoma 2 like protein 11 in human hepatocellular carcinoma cells. More interestingly, it was observed that LGK974 obviously enhances the tumor necrosis factor-related apoptosis-inducing ligand induced apoptosis. Our data indicated that LGK974 not only inhibited the Wingless-related integration site/beta catenin signaling pathway, but also inactivated the nuclear factor kappa light chain enhancer of activated B cells signaling pathway. We also activated nuclear factor kappa light chain enhancer of activated B cells signaling pathway by using small interfering RNA against nuclear factor of kappa light polypeptide gene enhancer in B-cells inhibitor alpha, which effectively attenuated the sensitization effects of LGK974 on tumor necrosis factor-related apoptosis-inducing ligand in human liver cancer cell line, HepG2 cells. Altogether, these data presented in this study illustrated that LGK974 potentiated the lethality of tumor necrosis factor-related apoptosis-inducing ligand in human hepatocellular carcinoma by inducing apoptosis via suppressing nuclear factor kappa light chain enhancer of activated B cells signaling pathway.

Key words: Human hepatocellular carcinoma, LGK974, drug resistance, apoptosis, nuclear factor kappa light chain enhancer of activated B cells signaling pathway

Human Hepatocellular Carcinoma (HCC) is the third leading cause of cancer mortality around the world, with approximately seven hundred thousand each year ${ }^{[1,2]}$. Even though the advance in chemotherapy and surgery in the past decades have been enhanced the survival time of HCC patients, a considerable part of patients still relapse due to the development of drug resistance to chemotherapeutics ${ }^{[3,4]}$. Therefore, to identify novel drugs to sensitize HCC to chemotherapy is hugely important for the exploration of therapies.

The Wingless-related integration site (Wnt) family comprised of 19 members which can be classified into two categories depending on whether beta $(\beta)$ catenin was involved. The canonical $\beta$-catenin dependent pathway and the non-canonical $\beta$-catenin independent pathway ${ }^{[5,6]}$. The unusual activation of $\mathrm{Wnt} / \beta$-catenin

*Address for correspondence

E-mail: chenxye@enzemed.com 
signaling has been reported to be involved in numerous cancer types ${ }^{[7-10]}$. Furthermore, several studies have indicated that $\beta$-catenin mutation was implicated in the tumorigenesis of multiple cancers, such as non-small cell lung cancer ${ }^{[11]}$, colorectal cancer ${ }^{[12]}$, ovarian cancer ${ }^{[13]}$, gastric cancer ${ }^{[14]}$, esophageal cancer ${ }^{[15]}, \mathrm{HCC}^{[16]}$ and so on. Recently, LGK974, a specific porcupine inhibitor, was found to potently inhibit Wnt signaling pathway ${ }^{[17]}$. LGK974 is at phase II of a clinical trial and is believed to possess a promising application in Wnt-driven cancers $^{[18,19]}$. However, there is little research focusing on the role of LGK974 in HCC up to now.

Tumor Necrosis Factor-Related Apoptosis-Inducing Ligand (TRAIL), one of Tumor Necrosis Factor (TNF) family members, has been diffusely identified as a hopeful anti-cancer drug to against a large group of tumors because of its selective cytotoxicity to cancer cells $^{[20,21]}$. After binding to receptors, TRAIL receptor 1 (TRAIL-R1) Death Receptor 4 (DR4) or TRAIL Receptor 2 (TRAIL-R2) Death receptor 5 (DR5), the binding complex recruits the intracellular adaptor Fas Associated Death Domain (FADD) and procaspase 8 to form the Death-Inducing Signaling Complex (DISC), which induces caspase- 8 self-cleavage and initiates an extrinsic pathway of apoptosis ${ }^{[22-24]}$. Unfortunately, TRAIL is still not effective in almost half of the detected cancer cell lines ${ }^{[25,26]}$. A previous study reported that most of HCC cell lines showed resistance to TRAILinduced apoptosis ${ }^{[27]}$. Therefore, the identification of the conventional drugs in new use to sensitivity to TRAIL may represent a reachable approach for effective $\mathrm{HCC}$ treatment.

In the present study, the effects of LGK974 alone and the sensitizing effects to TRAIL and the underlying molecular mechanisms in HCC was preliminarily elucidated.

\section{MATERIALS AND METHODS}

\section{Cell culture:}

Two HCC cell lines HepG2 and Huh7 were obtained from the American Type Culture Collection (ATCC, USA) and cultured in a humidified incubator in an atmosphere of $5 \%(\mathrm{v} / \mathrm{v})$ carbon dioxide $\left(\mathrm{CO}_{2}\right)$ at $37^{\circ}$ using Dulbecco's Modified Essential Medium (DMEM) (Hyclone; GE Healthcare Life Sciences) supplemented with $10 \%$ fetal bovine serum (FBS) (Hyclone; GE Healthcare Life Sciences), $100 \mathrm{U} / \mathrm{ml}$ penicillin (SigmaAldrich; Merck KGaA) and $100 \mathrm{~g} / \mathrm{ml}$ streptomycin (Sigma-Aldrich; Merck KGaA).

\section{Cell viability assay:}

The cytotoxicity of LGK974 and TRAIL alone or in combination with HCC cells in vitro was determined by 3-(4, 5-dimethylthiazolyl-2)-2, 5-diphenyltetrazolium bromide (MTT) assay. In brief, cells were seeded in a 96-well tissue culture plate and incubated with varying concentrations of LGK974 and TRAIL alone or in combination for another $24 \mathrm{~h}$. Then, MTT was added to each well at a final concentration of $5 \mathrm{mg} / \mathrm{ml}$ after that discard all medium and the plate was further incubated at $37^{\circ}$ for up to $4 \mathrm{~h}$. Then, Dimethyl Sulfoxide (DMSO, $150 \mu \mathrm{l})$ was added into each well and the plate was shaken to dissolve the formazan crystals. Finally, the absorbance of the mixture was measured at $570 \mathrm{~nm}$ using a microplate reader (Molecular Device).

\section{Colony formation assay:}

Briefly, after treated with different dose of LGK974, 1000 HCC cells were seeded into the 6-well plate followed by $14 \mathrm{~d}$ incubation. Then, cells were fixed with iced methanol for 20 min after washing with Phosphate Buffered Saline (PBS), followed by treatment with $0.1 \%$ crystal violet staining solution for $15 \mathrm{~min}$. All operations were performed at room temperature. After cells were washed with PBS twice, the number of colonies ( $>50$ cells) was counted by using an inverted microscope (Olympus Corp).

\section{Apoptotic analysis:}

Cell apoptosis rate was determined by using flow cytometry analysis. After indicated treatment, cells were collected by trypsinization and washed with ice-cold PBS followed by staining with Annexin V-Fluorescein Isothiocyanate (FITC) in dark at $4^{\circ}$ and Propidium Iodide (PI) for $5 \mathrm{~min}$ at room temperature. Then, flow cytometry assay was performed on a FluorescenceActivated Cell Sorting (FACS) Scan flow-cytometer (Becton Dickinson). Early apoptotic cells are Annexin V-positive and PI-negative (Annexin $\mathrm{V}-\mathrm{FITC}^{+} / \mathrm{PI}^{-}$), while late apoptotic cells are Annexin V/PI-doublepositive (Annexin $\mathrm{V}-\mathrm{FITC}^{+} / \mathrm{PI}^{+}$). The summation of both early and late apoptotic cells was used to determine the percentage of apoptotic cells. WinMDI 2.9 software was used to perform the data analysis.

\section{Western blotting:}

Cells were washed with PBS and protein was obtained by scraping in lysis buffer which contains aprotinin $(2.1$ $\mu \mathrm{g} / \mathrm{ml})$, leupeptin $(0.5 \mu \mathrm{g} / \mathrm{ml})$, phenylmethylsulfonyl fluoride $(1 \mathrm{~mm})$, Magnesium chloride $\left(\mathrm{MgCl}_{2}\right)$ (4.9 $\mathrm{mm})$, orthovanadate $(1 \mathrm{~mm})$ and $1 \%$ Triton X 100. The 
Bicinchoninic Acid (BCA) assay was used to determine the protein concentration and $20 \mu \mathrm{g}$ proteins for each sample was loaded on Sodium Dodecyl Sulphate Polyacrylamide Gel Electrophoresis (SDS-PAGE) and electrophoresis was performed at $100 \mathrm{~V}$ for $40 \mathrm{~min}$. The proteins were transferred onto Polyvinylidene Fluoride (PVDF) membranes and incubated with primary antibodies and respective secondary antibodies after blocking with $5 \%$ non-fat milk. X-ray film (Fujifilm) and Enhanced Chemiluminescence (ECL) reagents (GE Healthcare) were used to visualize the signal.

Primary antibodies caspase-3 (ab32351), Poly Adenosine Diphosphate-Ribose Polymerase (PARP) (ab32138), B-cell lymphoma 2 (Bcl-2) (ab32124), Bcl-2 homologous antagonist/killer (Bak) (ab32371), Bcl-2 associated agonist of cell death (Bad) (ab32445), Bcl-2-like protein 11 (Bim) (ab32158), N-cadherin (ab76011), E-cadherin (ab76055) and Vimentin (ab92547) used in the present study were obtained from Abcam (Cambridge, UK). Primary antibodies $\beta$-catenin (8480), Glycogen Synthase Kinase 3 Beta (GSK-3 $\beta$ )

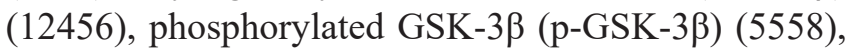
Inhibitor of Kappa B Kinase alpha (IKK $\alpha)$ (11930), phosphorylated IKK $\alpha$ (p-IKK $\alpha)$ (2697), Nuclear Factor Kappa Light Chain Enhancer of Activated B cells

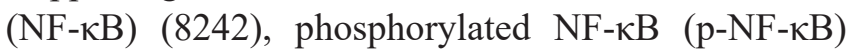
(3033), survivin (2808) and Nuclear Factor of Kappa Light Polypeptide Gene Enhancer in B-Cells Inhibitor, Alpha $(\mathrm{I} \kappa \mathrm{B} \alpha)$ (4814) were obtained from cell signaling technology (Danvers, MA, USA). The secondary antibodies were obtained from Santa Cruz (Dallas, TX, USA). The antibody against $\beta$-actin was purchased from Sigma-Aldrich (Merck KGaA).

\section{Immunocytochemistry assay for the nuclear translocation of NF-kB:}

For immunostaining, cells cultured on glass coverslips were fixed with iced $4 \%$ paraformaldehyde (20 min, room temperature) and washed with PBS for three times. Coverslips were then incubated sequentially with $0.5 \%$ Triton-X100 (Sigma) in PBS (5 min, room temperature), $5 \%$ BSA blocking buffer in PBS (60 min, room temperature), primary antibody against NF$\kappa \mathrm{B}$ (Abcam, Alexa Fluor $^{\circledR} 594$ conjugated) diluted in blocking buffer (overnight, $4^{\circ}$ ). Phalloidin was used to stain the cytoskeleton and nuclei were counterstained with $20 \mu \mathrm{g} / \mathrm{ml}$ of the nuclear stain 4',6-Diamidino-2Phenylindole (DAPI) (Sigma Aldrich) in PBS for 5 min. Coverslips were mounted on to glass slides using mounting media and pictures were obtained under fluorescence microscope (Olympus).

\section{Silencing of IкBa using Small interfering RNA (siRNA):}

For knockdown of the I $\kappa \mathrm{B} \alpha$, specific siRNA against $\mathrm{I} \kappa \mathrm{B} \alpha$ was purchased from Shanghai Genepharma and the sequence is 5'-GGACGAGAAAGATCATTGA-3'. The transfection was performed by using lipofectamine 2000 reagent (Thermofisher) according to the manufacture's instruction. The silence efficiency was confirmed by western blot assay.

\section{Statistical analysis:}

Statistical analysis was performed using a two-sided Student's t test for data containing two groups, or twoway Analysis Of Variance (ANOVA) (parametric) with a Bonferroni post-test for the comparison of multiple groups. All data are expressed as the mean \pm Standard Deviation (SD) from at least three independent experiments, $\mathrm{p}<0.05$ was considered to indicate a statistically significant $\left({ }^{*} \mathrm{p}<0.05, \quad * * \mathrm{p}<0.01\right) \quad$ and all statistical analysis done by GraphPad Prism 5.0 (GraphPad Software, Inc., La Jolla, CA, USA).

\section{RESULTS AND DISCUSSION}

LGK974 suppressed cell proliferation and colonies formation on HCC cells. Firstly, MTT assay was used to evaluate the cytotoxicity of LGK974 on HepG2 and Huh7 cells. As shown in fig. 1A, LGK974 significantly suppressed the cell survival of both HepG2 and Huh7 cell lines in a dose-dependent manner. Meanwhile, colony formation assay was performed to further confirm whether LGK974 could influence the ability of single cells to grow into colonies. Our data revealed that LGK974 treatment effectively decreased colony formation potentials of HepG2 and Huh7 cells (fig. 1B).

LGK974 effectively induced apoptosis in HCC cells by modulating Bcl-2 family. Next, to confirm whether the lethality effect of LGK974 on HCC was done by inducing apoptosis, flow cytometry analysis was performed. As shown in fig. 2A, it was found that LGK974 dramatically enhanced apoptosis rate in both two HepG2 and Huh7 cell lines (the percentage of cells under apoptosis increased from $6.93 \%$ to $12.81 \%$ and $28.76 \%$ and from $5.22 \%$ to $12.21 \%$ and $35.37 \%$ in HepG2 and Huh7 cells, respectively). Furthermore, the cleaved caspase- 3 and PARP, one of the hall markers for cell apoptosis, was also detected in both HepG2 and Huh7 cell lines after treated with LGK974 by western blot assay. Our data revealed that LGK974 effectively promoted the cleavage of caspase-3 and PARP in HepG2 and Huh7 cells (fig. 2B). 

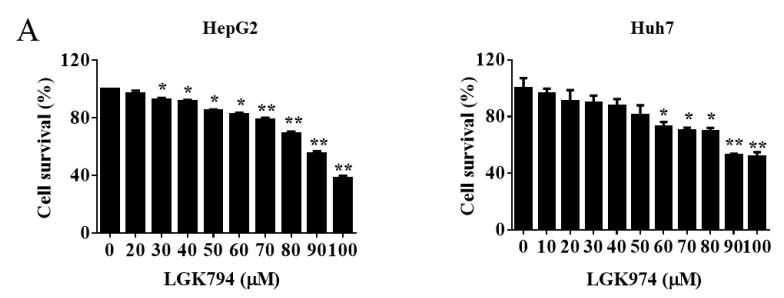

B

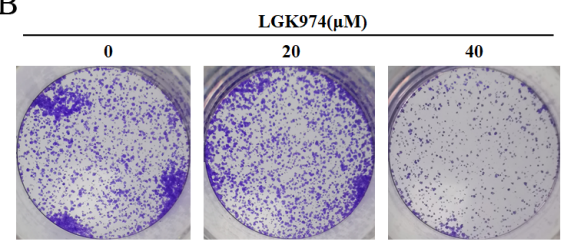

HepG2
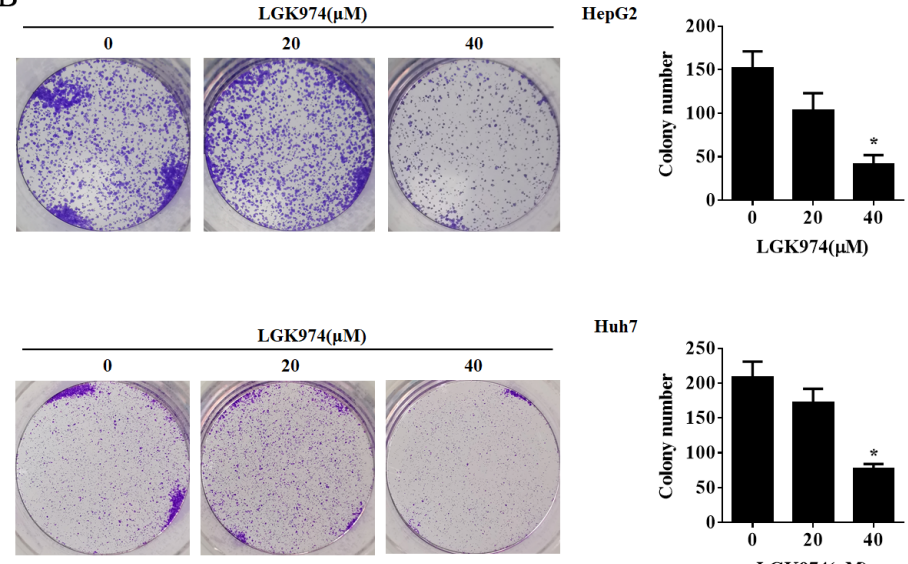

Huh7

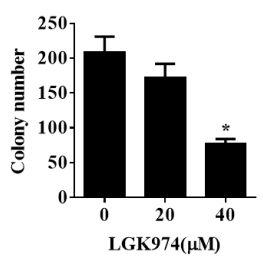

Fig. 1: LGK974 suppressed cell proliferation and colony formation on HCC cells. (A) LGK974 inhibited HCC cell growth in vitro. The HepG2 and Huh7 cells were incubated with varying concentrations of LGK974 for $24 \mathrm{~h}$. MTT assay was used to detect the cell viability; (B) Representative photographs of LGK974 on colony formation in HepG2 and Huh7 cells. *p<0.05 vs. control, **p<0.01 vs. control
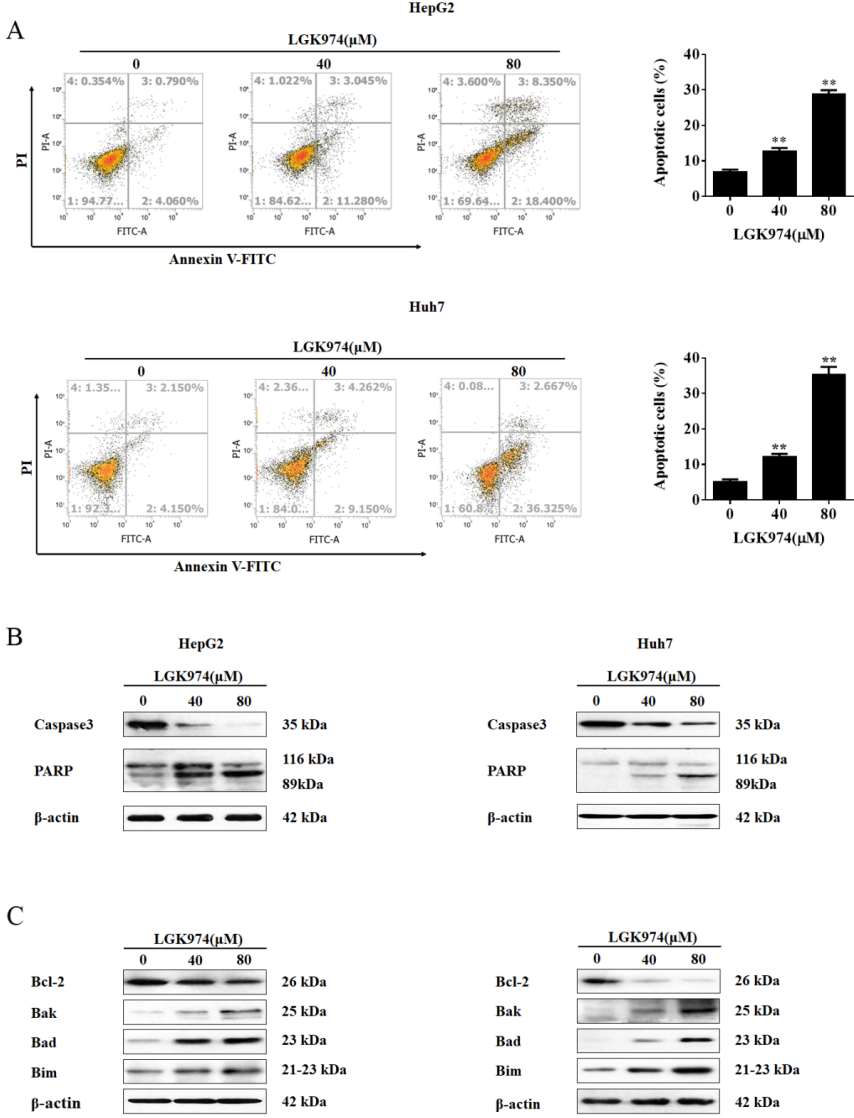

Fig. 2: LGK974 induced apoptosis in human HCC. The HepG2 and Huh7 cells were treated with different concentrations of LGK974 for $24 \mathrm{~h}$. (A) Cells were subjected to flow cytometry assay to detect the percentage of apoptotic cells. Data in the right corner represent the total of the percentages of Annexin V-FITC+cells; (B) The cleaved caspase-3 and PARP was determined by western blot assay; (C) Western blot assay was performed to evaluate the protein expression of Bcl-2 family. All data from three separate experiments were presented by mean \pm SD. ${ }^{*} p<0.05$ vs. control, $* * p<0.01 v s$. control 
Western blotting assays were also used to examine the Bcl-2 family proteins expression, as they are key regulators for the apoptosis pathway ${ }^{[28]}$. Our data indicated that LGK974 markedly decreased the level of Bcl-2 protein, while remarkably increased the levels of Bak, Bad and Bim proteins in HepG2 and Huh7 cells (fig. 2C), suggesting that LGK974 might trigger apoptosis procedure in $\mathrm{HCC}$ cells by regulating $\mathrm{Bcl}-2$ family protein expression at least partially.

LGK974 potentiated the TRAIL-mediated apoptosis in $\mathrm{HCC}$ cells via regulating Bcl-2 family expression. Next, MTT assay was used to examine whether LGK974 could increase TRAIL-mediated lethality in HCC cells. As expected, the combined treatment with LGK974 and TRAIL dramatically inhibited the cell growth in HepG2 and Huh7 cell lines (fig. 3A). To further confirm whether the sensitization functions of LGK974 on TRAIL-induced cytotoxicity was by inducing apoptosis, HepG2 cells were subjected to flow cytometry analysis after double staining with Annexin V-FITC and PI. As shown in fig. 3B, LGK974 significantly promoted the apoptosis induced by TRAIL in HepG2 cells, the apoptotic percentage increased from $10.37 \%$ (LGK974 alone) and $13.47 \%$ (TRAIL alone) to $44.71 \%$ (LGK974 in combination with TRAIL) (fig. $3 \mathrm{C})$.
A

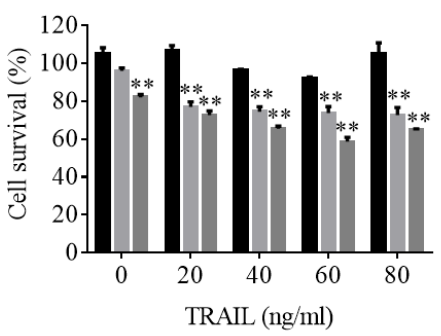

B

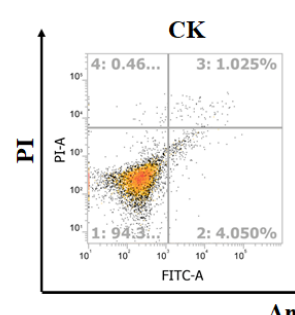

Annexin V-FITC

C

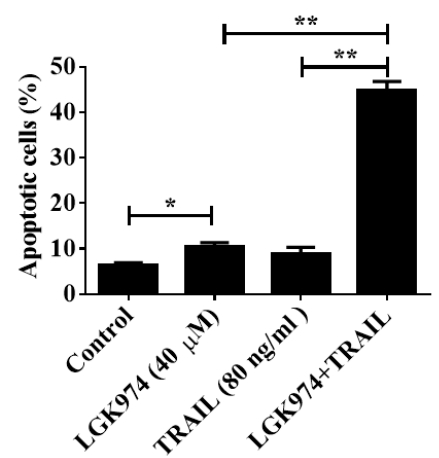

$\mathrm{D}$

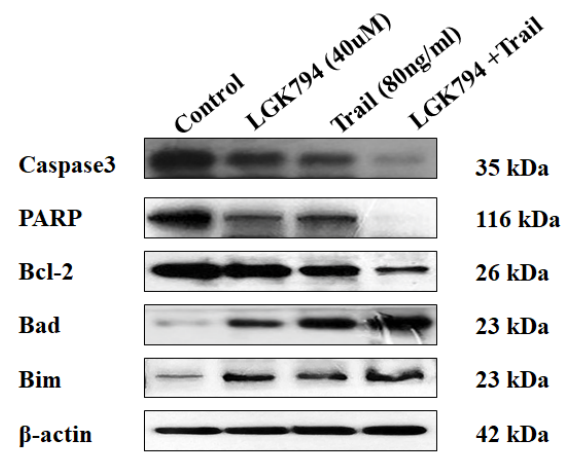

Fig. 3: LGK974 enhanced the TRAIL-mediated apoptosis in hepatocellular carcinoma. (A) Cell viability was determined by the MTT assay after HepG2 and Huh7 cells were incubated with different concentrations of LGK974 or/and TRAIL for 24 h. Data from three separate experiments were presented by mean \pm SD. ${ }^{*} p<0.05$ vs. control, ${ }^{*} p<0.01$ vs. control; (B) After HepG2 cells were treated as indicated, cells were subjected to flow cytometry assay to detect the percentage of apoptotic cells; (C) Apoptosis was quantified and presented in the histogram. Data from three separate experiments were presented by mean \pm SD. $* *$ p $<0.01$ vs. control. (D) Western blot assay was performed to detect the cleaved caspase-3 and PARP in HepG2 cells treated as indicated. Data from three

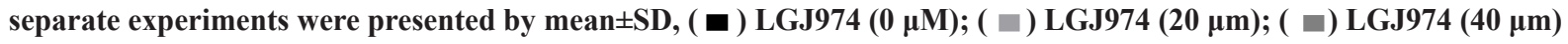


Meanwhile as shown in fig. 3D, the cleavage of caspase-3 and PARP was dramatically enhanced in HepG2 cells co-treated with LGK974 and TRAIL in HepG2. This finding was consistent with the data of FACS. Finally, Bcl-2 family proteins expression in HCC cells cotreated with LGK974 and TRAIL was also determined by western blot assay. Interestingly, co-treatment with LGK974 and TRAIL dramatically suppressed the Bcl2 protein expression and promoted the Bad and Bim proteins expression in HepG2 cells (fig. 3D). Taking together, all findings we elucidated that LGK974 could strengthen the TRAIL-induced apoptosis in HCC via increasing Bad and Bim expression.

LGK974 inhibited the activation of Wnt/ $\beta$-catenin and NF- $\kappa \mathrm{B}$ signaling pathways. As LGK974 is a potent Wnt inhibitor, we next examined the expression of $\beta$-catenin protein and the phosphorylation of its regulator GSK$3 \beta$ by western blot assay to determine the activation of Wnt signaling pathway. As shown in fig. 4A, LGK974 $(40 \mu \mathrm{m})$ alone indeed downregulated the protein expression of $\beta$-catenin and effectively decreased the phosphorylation of GSK-3 $\beta$. On the other hand, our data also revealed that LGK974 could significantly impair the activation of NF- $\mathrm{BB}$ signaling pathways, which was supported by the downregulation of the phosphorylation of IKK- $\alpha$ and NF- $\kappa$ B (fig. 4B). It was also observed that the expression of survivin, one of NF- $\kappa \mathrm{B}$ target genes was also suppressed by LGK974 (fig. 4B). Finally as shown in fig. 4C, the nucleartranslocation of NF- $\kappa \mathrm{B}$ was obviously inhibited by LGK-974 treatment in HepG2 cells. Taken together, the activation of $\mathrm{Wnt} / \beta$-catenin and $\mathrm{NF}-\kappa \mathrm{B}$ signaling pathways were inhibited by LGK974.

Consistent activation of NF- $\mathrm{KB}$ signaling pathway effectively attenuated the sensitizing effect of LGK974 on TRAIL in HCC cells. To further confirm whether NF- $\kappa B$ signaling pathway was involved in the role of LGK974 in HCC, especially its sensitizing function on TRAIL-mediated apoptosis, siRNA against IкB $\alpha$ was used to activate NF- $\kappa \mathrm{B}$. As shown in fig. 5A, the phosphorylation of $\mathrm{NF}-\kappa \mathrm{B}$ was effectively improved after I $\mathrm{KB} \alpha$ was silenced. Next, several downstream target gene of NF- $\kappa \mathrm{B}$ which contributed to the apoptotic pathway regulation were examined. As shown in fig. $5 \mathrm{~B}$, silence of I $\mathrm{KB} \alpha$ upregulated the expression of Bcl2 and survivin, and downregulated the expression of Bak, Bad and Bim. More interestingly, silence of I $\mathrm{B} \alpha$ significantly attenuated the apoptosis-induced by the combined treatment of LGK974 and TRIAL (as shown in fig. $5 \mathrm{C}$ and fig. 5D, the apoptosis rate was brought down from about $45 \%$ to about $23 \%$ ).
A

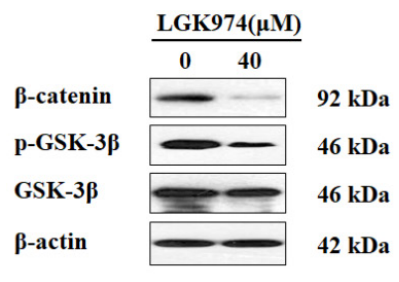

$\mathrm{C}$
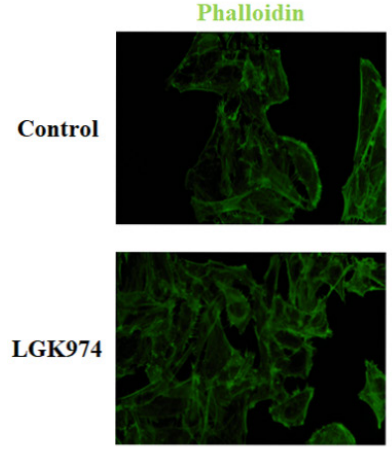

B

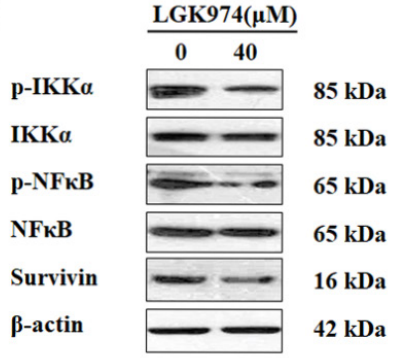


A

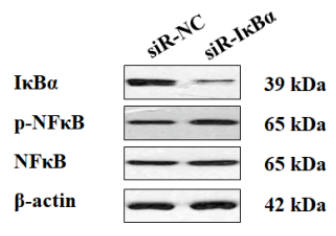

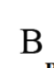

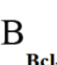

Bak

Bad

Bim

Survivin

$\beta$-actin

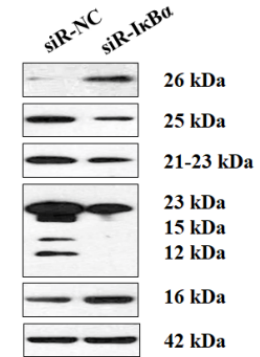

C
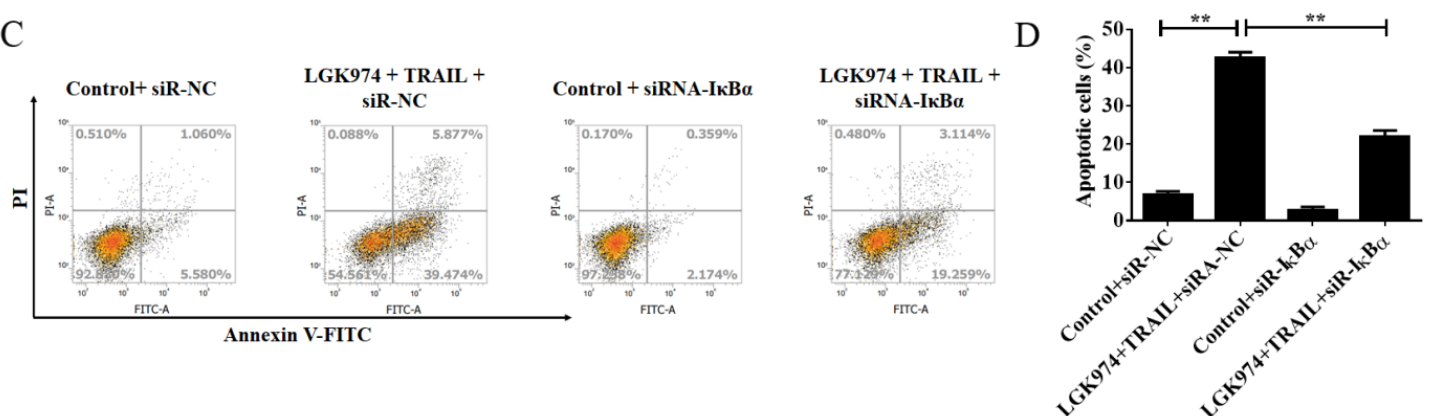

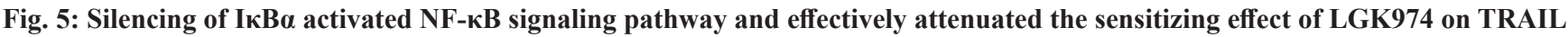
in HCC cells (A) The HepG2 cells were transfected with siRNA against IKB $\alpha$ or negative control (NC) for 24 h. The protein expres-

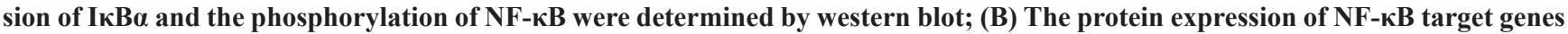
were determined by western blot; (C) The HepG2 cells were transfected with siRNA against IкB $\alpha$ or NC followed by the combined treatment of LGK974 and TRAIL. Cells were subjected to flow cytometry assay to detect the percentage of apoptotic cells; (D) Apoptosis rate was quantified and presented in the histogram. Data from three separate experiments were presented by mean \pm SD. $* * \mathbf{p}<0.01$ vs. control

Hepatocellular Carcinoma (HCC) is considered as the most common primary malignancy of the liver due to its high recurrence and mortality rates, and is more generally diagnosed in male ${ }^{[29,30]}$. In the early stage, $\mathrm{HCC}$ patients could usually benefit from chemotherapy ${ }^{[2,31]}$. However, almost all HCC patients can develop resistance to chemotherapeutics and this is a major challenge in healing cancer patients. TRAIL is a hopeful anti-cancer drug against a large group of cancers as it could specifically kill cancer cells with non-toxicity or low-toxicity on normal cells and tissues ${ }^{[25]}$. However, a lot of elements contribute to the development of acquirement resistance in cancer cell towards TRAIL. Many studies have proved that combined use of other anticancer agents with chemo-sensitization effects could conquer cancer cell resistance to TRAIL. In this study, we demonstrated that LGK974 could effectively enhance the TRAIL-mediated apoptosis in HCC cells.

Recently, several studies reported that the abnormal activation of Wnt signaling pathway contributed to the development of resistance of cancer cells to TRAIL $^{[32,33]}$. The biological role of LGK974, a novel Wnt antagonist, has been examined in multiple cancers. In pancreatic cancer cells, LGK974 was found to inhibit cell growth and triggered cell differentiation ${ }^{[34]}$. In breast cancer cells, LGK974 inhibited cell proliferation by enlarged Nuclear Receptor Binding Protein 1
$(\mathrm{NRBP} 1)^{[35]}$. It is also reported that LGK974 effectively suppressed the metastasis of head and neck squamous cell carcinoma ${ }^{[36]}$. All these findings authenticated that LGK974 exerted obvious anti-cancer characteristics including suppressing cell proliferation and metastasis of cancers. However, there is little study focus on the effect and the underlying mechanism of LGK974 in HCC, especially its chemo-sensitizing effects on TRAIL-mediated apoptosis up to now.

The present study tried to elucidate the anti-cancer biological functions and the underlying mechanism of LGK974 in HCC. Firstly, the data from MTT and colony formation assays proved that LGK974 exerted obvious cytotoxicity on HCC cell in a dose-dependent manner. Our data indicated that LGK974 alone could effectively induce apoptosis in HCC cells and significantly downregulated the $\mathrm{Bcl}-2$ protein expression, while upregulated the protein levels of Bak, Bad, Bim in HCC cells. It is well known that the abnormal expression of Bcl-2 family was a critical reason for the development of drug resistance in cancer ${ }^{[37]}$. As expected, our data illuminated that a sub-cytotoxic dose of LGK974 significantly sensitized TRAIL-induced apoptosis in HCC cells, which was supported by the activation of caspase-3 and PARP, since the cleavage of caspase and PRAP were the key biomarkers for the apoptosis pathway activation ${ }^{[38]}$. 
Evidences have proved that NF- $\kappa \mathrm{B}$ signaling pathway played an indispensable role in chemo-resistance in cancer and one of the mechanism is to promote its antiapoptotic target gene such as Bcl-2 family members ${ }^{[39]}$. Recently, two studies reported that there is a crosstalk between Wnt and NF- $\kappa B$ signaling pathways ${ }^{[40,41]}$. Therefore, we tried to elucidate whether NF- $\kappa$ B signaling pathway was involved in the sensitizing functions of LGK974 in HCC in this study. Our data indeed shown LGK974 exerted a remarkable role on Wnt signaling pathway, which was verified by the decreased levels of $\beta$-catenin protein and the phosphorylation of GSK-3 $\beta$. On the other hand, LGK974 effectively downregulated the phosphorylation of IKK $\alpha$ and NF- $\kappa \mathrm{B}$, as well as the expression of survivin, which imply the agent could weaken the NF- $\kappa \mathrm{B}$ signaling pathways. This finding was further supported by the data of immunocytochemistry in which the nuclear-translocation of NF- $\kappa \mathrm{B}$ was whittled.

Next, siRNA against I $\kappa \mathrm{B} \alpha$ was applicated in HepG2 cells to activate the NF- $\kappa$ B signaling pathway. Our data demonstrated that silencing of I $\mathrm{B} \alpha$ not only elevated the phosphorylation of NF- $\kappa \mathrm{B}$, but also promoted the expression of anti-apoptotic target genes such as Bcl2 and survivin, and suppressed the expression of proapoptotic target genes including Bak, Bad and Bim. The most important is that silencing of I $\mathrm{B} \alpha$ could effectively attenuate the apoptosis-induced by the combined treatment of LGK974 and TRAIL.

Taken together, all data in this study we indicate that LGK974 exerted significant cytotoxicity on HCC and effectively enhanced TRAIL-mediated lethality by inducing apoptosis via modulating the activation of NF- $\mathrm{KB}$ signaling pathways and the expression of downstream target genes including Bcl-2 family and survivin. In conclusion, our findings afford a novel insight into the clinical application of LGK974 in HCC and underlying mechanisms.

\section{Author's contributions:}

Weiti Wu and Fei Yan contributed equally to this work. Conception, design and administrative support were contributed by Weiti Wu and Xiaoye Chen. Provision of study materials or patients was contributed by Huazhong Chen and Hui Shao. Collection and assembly of data was done by Fei Yan and Yongzhi Tang. Data analysis and interpretation was done by Weiti Wu, Fei Yan and Yongzhi Tang. Manuscript writing and final approval of manuscript was contributed by all authors.

\section{Acknowledgements:}

This work was supported by Science and Technology Project of Taizhou (No. 1801KY15).

\section{Conflicts of interest:}

All authors have completed the ICMJE uniform disclosure form. The authors have no conflicts of interest to declare.

\section{REFERENCES}

1. Bray F, Ferlay J, Soerjomataram I, Siegel RL, Torre LA, Jemal A. Global cancer statistics 2018: GLOBOCAN estimates of incidence and mortality worldwide for 36 cancers in 185 countries. CA Cancer J Clin 2018;68(6):394-424.

2. Chang H, Zou Z. Targeting autophagy to overcome drug resistance: further developments. J Hematol Oncol 2020;13(1):1-8.

3. Singh MP, Cho HJ, Kim JT, Baek KE, Lee HG, Kang SC. Morin hydrate reverses cisplatin resistance by impairing PARP1/HMGB1-dependent autophagy in hepatocellular carcinoma. Cancers 2019;11(7):986.

4. Anwanwan D, Singh SK, Singh S, Saikam V, Singh R. Challenges in liver cancer and possible treatment approaches. Biochim Biophys Acta 2020;1873(1):188314.

5. Caspi M, Wittenstein A, Kazelnik M, Shor-Nareznoy Y, Rosin-Arbesfeld R. Therapeutic targeting of the oncogenic wnt signaling pathway for treating colorectal cancer and other colonic disorders. Adv Drug Deliv Rev 2020.

6. He S, Tang S. WNT/ $\beta$-catenin signaling in the development of liver cancers. Biomed Pharmacother 2020;132:110851.

7. Sherwood V. WNT signaling: an emerging mediator of cancer cell metabolism? Mol Cell Biol 2015;35(1):2-10.

8. Nusse R, Clevers H. Wnt/ $\beta$-catenin signaling, disease and emerging therapeutic modalities. Cell 2017;169(6):985-99.

9. Juanes M. Cytoskeletal control and Wnt signaling-APC's dual contributions in stem cell division and colorectal cancer. Cancers 2020;12(12):3811.

10. McCracken KW, Aihara E, Martin B, Crawford CM, Broda $\mathrm{T}$, Treguier $\mathrm{J}$, et al. Wnt $/ \beta$-catenin promotes gastric fundus specification in mice and humans. Nature 2017;541(7636):1827.

11. Yu JE, Ju JA, Musacchio N, Mathias TJ, Vitolo MI. Long noncoding RNA DANCR activates Wnt/ $\beta$-catenin signaling through MiR-216a inhibition in non-small cell lung cancer. Biomolecules 2020;10(12):1646.

12. Zhu GX, Gao D, Shao ZZ, Chen L, Ding WJ, Yu QF. Wnt/ $\beta$-catenin signaling: Causes and treatment targets of drug resistance in colorectal cancer. Mol Med Rep 2021;23(2):1.

13. Sun Z, Xu S, Cai Q, Zhou W, Jiao X, Bao M, et al. Wnt/ $\beta$ catenin agonist $\mathrm{BIO}$ alleviates cisplatin-induced nephrotoxicity without compromising its efficacy of anti-proliferation in ovarian cancer. Life Sci 2020;263:118672.

14. Yu Z, Jiang X, Qin L, Deng H, Wang J, Ren W, et al. A novel UBE2T inhibitor suppresses Wnt/ $\beta$-catenin signaling hyperactivation and gastric cancer progression by blocking RACK1 ubiquitination. Oncogene 2021;40(5):1027-42.

15. Zhao D, Wang B, Chen H. RAB11A mediates the proliferation and motility of esophageal cancer cells via WNT signaling pathway. Acta Biochim Pol 2020;67(4):531-8. 
16. Singh G, Hossain MM, Bhat AQ, Ayaz MO, Bano N, Eachkoti $\mathrm{R}$, et al. Identification of a cross-talk between EGFR and Wnt/ beta-catenin signaling pathways in HepG2 liver cancer cells. Cell Signal 2021;79:109885.

17. Liu J, Pan S, Hsieh MH, Ng N, Sun F, Wang T, et al. Targeting Wnt-driven cancer through the inhibition of Porcupine by LGK974. Proc Natl Acad Sci USA 2013;110(50):20224-9.

18. Guimaraes PP, Tan M, Tammela T, Wu K, Chung A, Oberli M, et al. Potent in vivo lung cancer Wnt signaling inhibition via cyclodextrin-LGK974 inclusion complexes. J Control Release 2018;290:75-87.

19. Li J, Wu G, Xu Y, Li J, Ruan N, Chen Y, et al. Porcupine inhibitor LGK974 downregulates the Wnt signaling pathway and inhibits clear cell renal cell carcinoma. Biomed Res Int 2020.

20. Ashkenazi A, Pai RC, Fong S, Leung S, Lawrence DA, Marsters SA, et al. Safety and antitumor activity of recombinant soluble Apo2 ligand. J Clin Invest 1999;104(2):155-62.

21. Cao Y, Kong S, Xin Y, Meng Y, Shang S, Qi Y. Lestaurtinib potentiates TRAIL-induced apoptosis in glioma via CHOPdependent DR5 induction. J Cell Mol Med 2020;24(14):782940.

22. Carneiro BA, El-Deiry WS. Targeting apoptosis in cancer therapy. Nat Rev Clin Oncol 2020;17(7):395-417.

23. Hanahan D, Weinberg RA. Hallmarks of cancer: the next generation. Cell 2011;144:646-74.

24. Yuan X, Gajan A, Chu Q, Xiong H, Wu K, Wu GS. Developing TRAIL/TRAIL death receptor-based cancer therapies. Cancer Metastasis Rev 2018;37(4):733-48.

25. Deng D, Shah K. TRAIL of hope meeting resistance in cancer. Trends Cancer 2020;6(12):989-1001.

26. Zhang L, Fang B. Mechanisms of resistance to TRAIL-induced apoptosis in cancer. Cancer Gene Ther 2005;12(3):228-37.

27. Shin EC, Seong YR, Kim CH, Kim H, Ahn YS, Kim K, et al. Human hepatocellular carcinoma cells resist to TRAILinduced apoptosis, and the resistance is abolished by cisplatin. Exp Mol Med 2002;34(2):114-22.

28. Lu Y, Bian D, Zhang X, Zhang H, Zhu Z. Inhibition of Bcl-2 and $\mathrm{Bcl}-\mathrm{xL}$ overcomes the resistance to the third-generation EGFR tyrosine kinase inhibitor osimertinib in non-small cell lung cancer. Mol Med Rep 2021;23(1):1.

29. Peng CX, Ai-di Zhang BC, Yang BJ, Wang QH, Yang M, Wei SH. Macular thickness as a predictor of loss of visual sensitivity in ethambutol-induced optic neuropathy. Neural Regen Res 2016;11(3):469-75.

30. Siegel R, Naishadham D, Jemal A. Cancer statistics, 2012. CA Cancer J Clin 2012;62:10-29.

31. Asano Y, Arakawa S, Ito M, Kato H, Shimura M, Hayashi C, et al. A case of metachronous liver metastasis of gallbladder cancer successfully treated by hepatectomy after chemotherapy. Gan To Kagaku Ryoho 2020;47(10):1501-4.
32. Zimmerman ZF, Kulikauskas RM, Bomsztyk K, Moon RT, Chien AJ. Activation of $\mathrm{Wnt} / \beta$-catenin signaling increases apoptosis in melanoma cells treated with trail. PLoS One 2013;8(7):e69593.

33. Doubravska L, Simova S, Cermak L, Valenta T, Kořínek V, Anděra L. Wnt-expressing rat embryonic fibroblasts suppress Apo2L/TRAIL-induced apoptosis of human leukemia cells. Apoptosis 2008;13(4):573-87.

34. Jiang X, Hao HX, Growney JD, Woolfenden S, Bottiglio C, $\mathrm{Ng} \mathrm{N}$, et al. Inactivating mutations of RNF43 confer Wnt dependency in pancreatic ductal adenocarcinoma. Proc Natl Acad Sci USA 2013;110(31):12649-54.

35. Wei H, Wang H, Ji Q, Sun J, Tao L, Zhou X. NRBP1 is downregulated in breast cancer and NRBP1 overexpression inhibits cancer cell proliferation through Wnt/ $\beta$-catenin signaling pathway. Onco Targets Ther 2015;8:3721-30.

36. Rudy SF, Brenner JC, Harris JL, Liu J, Che J, Scott MV, et al. In vivo Wnt pathway inhibition of human squamous cell carcinoma growth and metastasis in the chick chorioallantoic model. J Otolaryngol Head Neck Surg 2016;45(1):1-8.

37. Maji S, Panda S, Samal SK, Shriwas O, Rath R, Pellecchia M, et al. Bcl-2 antiapoptotic family proteins and chemoresistance in cancer. Adv Cancer Res 2018;137:37-75.

38. Saraste A, Pulkki K. Morphologic and biochemical hallmarks of apoptosis. Cardiovasc Res 2000;45(3):528-37.

39. Godwin P, Baird AM, Heavey S, Barr M, O’Byrne K, Gately KA. Targeting nuclear factor-kappa $\mathrm{B}$ to overcome resistance to chemotherapy. Front Oncol 2013;3:120.

40. Lin Y, Higashisaka K, Shintani T, Maki A, Hanamuro S, Haga $\mathrm{Y}$, et al. Progesterone receptor membrane component 1 leads to erlotinib resistance, initiating crosstalk of $\mathrm{Wnt} / \beta$-catenin and NF- $\kappa \mathrm{B}$ pathways, in lung adenocarcinoma cells. Sci Rep 2020;10(1):1-10.

41. Jang J, Song J, Lee H, Sim I, Kwon YV, Jho EH, et al. LGK974 suppresses lipopolysaccharide-induced endotoxemia in mice by modulating the crosstalk between the $\mathrm{Wnt} / \beta$-catenin and NF-кB pathways. Exp Mol Med 2021;53(3):407-21.

This is an open access article distributed under the terms of the Creative Commons Attribution-NonCommercial-ShareAlike 3.0 License, which allows others to remix, tweak, and build upon the work non-commercially, as long as the author is credited and the new creations are licensed under the identical terms

This article was originally published in a special issue, "Novel Therapeutic Approaches in Biomedicine and Pharmaceutical Sciences" Indian J Pharm Sci 2021:83(6) Spl Issue "29-37" 